\title{
Identifying Key Technologies in Saskatchewan, Canada: Evidence from Patent Information
}

\author{
Li Zhang \\ University of Saskatchewan Library \\ Geology Building \\ 114 Science Place \\ Saskatoon SK S7N 5E2 \\ Canada \\ Phone: 01-306- 966-6049 \\ Fax: 01-306-966-1911 \\ E-mail: li.zhang@usask.ca
}

\begin{abstract}
This study attempts to identify the areas of technological strength of the province of Saskatchewan, Canada, whose economy is heavily based on natural resources, by analyzing patent information. 606 US patents held by Saskatchewan organizations were identified. The results show that inventive activities are steadily growing and Saskatchewan's technological development has experienced three stages. The Initial stage (1971-1985) was dominated by traditional resource-based technologies; the Emerging stage (1986-1995) was characterized by the emergence of new technologies in the Drugs \& Medical field; and the Developing stage (1996-2009) was marked by more of a balance between traditional and new technologies. In Canada and worldwide, inventive activities in Computers \& Communication field have been most prominent since the last decade. However, Saskatchewan demonstrates a different path from the rest of the world. While traditional technological fields still dominate in the province, it is gradually building its strength in Drugs \& Medical field. The results present a possibility to diversify the provincial economy if policy makers develop strategies to facilitate the transfer of new technologies to industries.
\end{abstract}

Keywords: Patent, Saskatchewan Canada, Technology 


\section{Introduction}

Patents are viewed by many global organizations as one of the indicators of science and technology performance. Patent analysis has been used as an effective technique to evaluate technological competence and potential, discover core technologies, measure research outputs, and predict technological trends in a field, institution, region, or nation. As summarized by OECD, the unique characteristics of patent documents make them a reliable resource for such study [1]. Patents cover almost every field of technology, which makes it possible to obtain a comprehensive picture of a nation or region's involvement in technology. Second, each patent is assigned a set of highly detailed classification codes, which provides the opportunity for different levels of aggregation. Inventions can be categorized from broad fields of technological sectors to more specific sub-sectors. Third, patent documents contain an abundance of additional information, such as application date, issuing date, assignee name, assignee locations, etc. These data can be used for various other analyses including tracing a nation's technological changes.

However, it should be noted that patent analysis has limitations as well. Not all inventions are patented, and patenting behaviours differs across industries and countries and across time. Further, the value distribution of patents is often skewed with only a few have high technical and economical value. Simple patent counts give each patent the same weight, thus the results can be misleading, especially when the sample size is small [1]. Therefore, results from patent analysis must be used and interpreted with caution.

Worldwide, many studies have applied patent analysis to explore the technological development trends in different countries or regions. For example, in two researches, patent analysis techniques were used to measure the technological changes in Norway and Germany respectively $[2,3]$. Chen and colleagues identified the core technologies and key industries of Taiwan by using patent counts and patent classification codes [4]. In Canada, a few researchers have used these techniques to study the technological trends at national level or at technical field level. In a study comparing the Canadian patents in USPTO with all USPTO patents from 1967-1994, Trahtenberg concluded that the technological composition of Canadian patents was out of step with other countries as traditional fields still prevailed in Canada and high tech fields were far behind the rest of the world [5]. More recently, Yegul and colleagues studied patents in the field of nanotechnology from 1976-2004 and found that Canada ranked at $5^{\text {th }}$ place in this field [6]. The present study is an attempt to apply patent analysis in a specific region of Canada, the province of Saskatchewan.

Saskatchewan is one of the three prairie provinces of Canada. The production and export of agricultural products, natural resources, and their refined products are the backbone of the Saskatchewan economy. About $95 \%$ of all goods produced in the province directly depend on its agricultural and natural resources [7]. The agricultural product sector in Saskatchewan accounted for $10 \%$ of world trade in wheat, $60 \%$ in durum, and $40 \%$ in canola in 2001 . 
Saskatchewan is also blessed with abundant natural resources. The province is the largest uranium-producing region in the world, accounting for $25 \%$ of annual uranium production in 2002. With an estimated $75 \%$ of the world's potash (one of the three primary crop nutrients) reserves, it is the one of the largest potash producers in the world. The province is also a significant producer of crude oil and natural gas, accounting for $20 \%$ of Canada's oil production.

The increase in commodity prices from 2006 until the third quarter of 2008 has contributed significantly to the economic boom in Saskatchewan. For example, the sales of oil in this province increased from $\$ 8,376 \mathrm{M}$ in 2007 to $\$ 13,321 \mathrm{M}$ in 2008 , an increase of $59 \%$. In the same period, the sales of potash increased from $\$ 3,056 \mathrm{M}$ to $\$ 7,405 \mathrm{M}$, an increase of $142 \%$ [8]. In the last two decades, the world economy has become increasingly technology-oriented, particularly with the scientific and technological advances in the fields of information and communication technology and biotechnology [9]. Traditional advantages in natural resources such as agricultural products, energy resources, and other commodities are no longer the most important factor to determine a nation or region's competitiveness. Further, commodity prices can be volatile, thus making the revenue from natural resources unpredictable. For example, the wide-spread financial turmoil in late 2008 resulted in a sharp decline in commodity prices. The crude oil price dropped from US $\$ 140 /$ barrel in July 2008 to US $\$ 38 /$ barrel in January 2009. The price of potash was $\$ 185 /$ Ton in 2007 , soared to $\$ 860 /$ Ton in January 2009 , and then fell to $\$ 360 /$ Ton in January 2010 [10]. The same volatility can be found in agricultural products. The wheat price was $\$ 6.78 /$ bushel in March 2008, but it slipped to $\$ 4.85 /$ bushel in 2009 [11]. These examples demonstrate that, while the resource-based economy benefited Saskatchewan during the boom years, it is unpredictable and vulnerable.

During the last decade, Saskatchewan has increased its investment in research and development $(R \& D)$, and several large research facilities such as the Canadian Light Source and Innovation Place have been established. Because patents are often considered as an indicator of technology output and R\&D performances [1], this study will analyze patent activities in the province, hoping to provide evidence for future policy directions.

Specifically, the research purposes are:

- To identify key technologies in Saskatchewan

- To show changes in key technologies in Saskatchewan, if any

- To find out if the province has development potential in high technology fields. In this study, high technology is defined as technology in fields considered as the engines of the new economy: computers \& communications, and drugs \& medical including biotechnology [12]

- To identify key organizations contributing to innovation in the province

\section{Methods}


Delphion Intellectual Property Network database was searched to identify patents held by Saskatchewan organizations (including individuals) in May 2009. The field searched was "patent assignee" because it provides locations of assignees. The search string is listed in Appendix. The collection searched was US Patents because the United States is generally recognized as the largest technological market, and most inventors tend to file their patent applications in the United States. The results were exported to an Access database for analysis. The location of assignees for each patent was further examined to make sure they are indeed patents from this province.

There are three types of patents: utility, design, and plant patents. It is generally agreed that only utility patents represents real inventive or innovative activities, therefore, only utility patents were included in this study.

The application date and issuing date of each patent were recorded. These data allow for further analysis of Saskatchewan's key technologies over different time periods. The number of assignees of each patent was counted in order to find out if the invention was a collaborative effort. A collaborative patent is defined as a patent with more than one assignee. For collaborative patents, locations of all the assignees were recorded in order to find collaboration patterns. The names of Saskatchewan assignees were recorded to identify key contributors to the technological developments in this province.

In order to identify key technologies in this province, a classification scheme for technological sectors and sub-sectors developed by Hall and colleagues was used [13]. Each US patent is assigned a series of classification class and subclass based on the highly detailed US patent classification system for technology, which includes 400 classes and 120,000 subclasses. In Hall's classification scheme, the 400 classes are aggregated into 6 main technological sectors and 36 sub-sectors. The 6 main sectors are Chemical (excluding Drugs), Computers and Communications, Drugs and Medical, Electrical and Electronics, Mechanical, and Others. Because each patent document is usually assigned a series of classification codes including a main class and supplementary classes, the main class was used to convert each patent to the relevant technological sector and sub-sector in this study.

To discover the types of organizations involved in inventive activities, patents were categorized by an institutional classification based on assignee names, which was modified based on a model developed by Bhattacharya [12]. This modified classification includes five types of institutions: industry, research institute, university, individual, and others.

\section{Results}

631 patents were retrieved from the Delphion database, among which 25 were design patents, thus 606 utility patents were included in this study.

\subsection{Patents owned by Saskatchewan by Issuing Year}


The first Saskatchewan-held US patent was granted in 1971, with 3 patents issued in that year. The detailed distribution of patents by 5 -year periods is shown in Figure 1 . The patent development process in Saskatchewan can be divided into three stages. During the initial stage, from 1971-1985, the number of patents owned by Saskatchewan organizations was sparse, with less than 10 patents granted each year. During the emerging stage, from 19861995 , the number of patents granted each year increased to 21 on average each year. In the developing stage, from 1996-2009, the number of patents granted each year jumped to 30 . It was noted that only 72 patents were granted during the period of 2006-2009. Two reasons might account for this. First, this period only includes 3.5 years because the search was done in May 2009, whereas other periods covered five years. Second, the comparison between the patent application date and patent issuing date shows that there is a three year lag between the two dates. Therefore, it is quite possible that patents applied for during this period have not been granted yet.

\section{Insert Figure 1 here}

\subsection{Patenting by Institution Type}

The patent assignees were classified into five types of institutions: industry, research institute, university, individual, and others. Of the 606 included patents, industry contributed the majority of the inventive activity $(438 ; 74 \%)$ in this province, followed by university with 115 patent (17\%). The other three types of organizations (individual, research institute, and others) contributed $8.7 \%$ of the patenting activity. The others category mainly consists of Saskachewan provincial government agencies and Canadian federal government agencies located in Saskatchewan. See figure 2 for the detailed number of patents for each category.

\section{Insert Figure 2 here}

The 606 patents were contributed by 266 organizations or individuals. When numbers of patents owned by each assignee is examined, it becomes clear that the majority of assignees own a small number of patents. There are 258 assignees (97\%) with fewer than 10 patents, and only 8 assignees (3\%) own more than 10 patents. The assignees with more than 10 patents are listed in Table 1. Among them, the University of Saskatchewan is ranked first with 114 patents, follwed by Flexi-Coil Limited with 85 patents. The number of patents owned by the other 6 assignees who hold more than 10 patents is significantly smaller than that held by the two most productive assignees, ranging from 11-16 patents.

\section{Insert Table 1 here}

When it comes to the view of collaborative patents, 573 patents are owned by a single assignee, 26 by 2 assignees, and 7 by 3 assignees. In other words, 33 patents (5.4\%) are collaborative patents. Among the 33 collaborative patents, 9 were the result of in-province 
collaborations, 11 of national collaborations, and 13 of international collaborations. The collaborating countries include the United States, France, Great Britain, and Austria.

\subsection{Key Technology}

Each patent was classified into a technological sector and sub-sector based on Hall's technological classification scheme. Others category is the dominant technological sector $(40 \%)$ in Saskatchewan, followed by Drugs \& Medical (22\%) and Mechanical (18\%). The inventive activities in Chemical, Computers \& Communications, and Electrical \& Electronic are somewhat weak, accounting for only $20 \%$ of the total patents. Figure 3 highlights the patent activities in the various technological sectors in the province from 1971-2009.

\section{Insert Figure 3. here}

In addition to identifying the key patent technologies from 1971 to 2009, this study also compared the key patent techonolgies in the three patent development stages: the initial stage 1971-1985, the emerging stage 1986-1995, and the developing stage 1996-2009. This comparison will provide a foundation for a comprehensive understanding of Saskatchewan's technological development history. Table 2, 3, and 4 shows the detailed rank of technologies in the three stages.

Stage 1: Initial Stage 1971-1985

Technologies during the period from 1971-1985 were heavily dominated by the traditional sectors. The Others sector accounted for almost $50 \%$ of the patents, the Mechanical sector $19.35 \%$, and the Chemical $11.83 \%$. These three traditional technological sectors accounted for $79 \%$ of the total patent activity. The activities in the Electrical \& Electronic, Computers \& Communications, and Drugs \& Medical sectors were very low, with only $21 \%$ of the total patents. These results indicate that during the early stage of the technological development, Saskatchewan's technologies were focused on traditional sectors, reflecting the nature of province's natural resource-based economy.

\section{Insert Table 2 here}

Stage 2: Emerging Stage 1986-1995.

As shown in Table 3, the Others category was still ranked in first place in terms of number of patents granted, but its share dropped to $33 \%$. The Mechanical category was ranked in second place with a ratio of $26 \%$. The Drugs \& Medical sector underwent the most noticeable change during this stage. It was ranked last in the Initial Stage, but it showed rapid growth and became the third ranked technological sector in the Emerging stage. The share of Drugs \& Medical increased from $2.15 \%$ in the previous stage to $14.69 \%$. This significant growth indicates that new technology was beginning to emerge as a key technology in this province. The percentages for the rest of technology sectors were somewhat stable. 
Insert Table 3 here

Stage 3: Developing Stage 1996-2009

In this stage, the Others sector continued to be the most important technology with a $41 \%$ share of the total patents. The Drugs \& Medical sector kept on its development speed, and is ranked at second place with a striking increase of its share to $30 \%$. Mechanical is still in the third place but the percentage has dropped to $14 \%$. The percentage of the Chemical category dropped to below $10 \%$ for the first time in this stage, while the percentages of Electrical \& Electronic and Computers \& Communications did not change significantly. It is clear that in this phase, Saskatchewan's key technology continues to be based on traditional technology, but high technology has become one of the most important technological sectors.

Insert Table 4 here

\subsection{Technological Sub-sectors}

Hall's technology classification scheme includes 36 technological sub-categories, among which Saskatchewan's patents address 30 sub-categories. This study identified 12 core technology specializations. A core technology specialization is defined as a technological subcategory with a patent ratio of more than $1 \%$. The core technology specializations are shown in table 5. The top five core technology specializations are Earth Working \& Wells (under the Others sector), Drugs (under the Drugs \& Medical sector), Agriculture, Husbandry, Food (under the Others sector), Miscellaneous-Mechanical, and Biotechnology (under the Drugs \& Medical sector). The patent ratio of the sub-sectors of Earth Working \& Wells and Agriculture, Husbandry, Food combined is $29 \%$. The high percentages contributed by these two subsectors are a reflection of Saskatchewan's strengths in mining, agricultural and other natural resource fields. The Drugs and Biotechnology sub-sectors, which represent new and high technology, have a ratio of $22 \%$. This analysis shows that while traditional technology specializations still prevail in this region, the specializations in Drugs and Biotechnology are becoming more and more important for innovation in this province.

Insert Table 5 here.

\subsection{Comparison of Technological Composition}

While the absolute terms about patents in Saskatchewan reveal its technological development history, it is unclear whether the development is driven by region specific forces or by national or technological forces which affect this region as well as other regions. In order to understand the technological development in this region from a broader perspective, Canadian patents in USPTO and all USPTO patents granted from 1995 to 2008 were chosen for comparison. Because a previous study compared Canadian patents with the rest of the world from 19671994 [5], the time period chosen for this study seems appropriate. 
Figure 5 compares the six technological categories of Saskatchewan patents with Canadian patents and all U.S. patents for the period of 1995-2008. Worldwide, there was little change in terms of the share of the six categories from 1995-2002 with just a slow decline in Others and Chemical fields. There was no obvious dominant field in this period with the share of each category ranging from $10 \%-20 \%$. Starting from 2003, number of inventions in Computers \& Communications (C\&C) field started to proliferate, and its share steadily ranked in the first place since then with a share of $32 \%$ in 2008 . The share of the second ranked category Electrical \& Electronic (E\&E) is somewhat stable from 2003 with a share about $22 \%$. The shares of the three traditional fields (Chemical, Mechanical, and Others) were gradually declining. Interestingly, Drugs \& Medical still ranked the lowest worldwide.

In Canada, the trend was different from the rest of the world from 1995-2003.The Others field clearly excelled the other five technological sectors in this period, but its share gradually declined from $33 \%$ to $23 \%$. During this period the share of Computers \&Communications steadily increased. From 2004, the increase in Computers \&Communications accelerated, and it ranked the first place among the six categories since then with a share of $35 \%$ in 2008 . The graph indicates that at the national level, Canada's technological development trend has been roughly the same as the rest of the world from 2004 as Computers \& Communications category outpaced all other five categories. But the figure of Saskatchewan tells another story. Though the graph is not smooth possibly because of the relative small patent numbers, one can still find that the trend is quite different from Canada or the rest of the world. The number of patents in Others field almost did not show signs of declining with a share around $40 \%$ from 1995-2003. Unlike at Canada national level or at the worldwide level, Drugs \& Medical field is nearly as important as Others field in this region particularly since 2003. Computers \& Communications and Electrical \& Electronic fields are almost always at the bottom of the graph.

$$
\text { Insert Figure } 4 \text { here. }
$$

\section{Discussion}

Innovation is one of the key factors necessary for an organization or a region to remain competitive, and spending on R\&D has increased significantly worldwide [14]. With the increasing spending on $R \& D$, the number of patents, an indication of R\&D output, has also been proliferating worldwide. This research demonstrates that Saskatchewan is following a similar trend. Based on data from Statistics Canada, domestic spending on research and development in Saskatchewan increased from $\$ 254 \mathrm{M}$ in 1995 to $\$ 441 \mathrm{M}$ in 2007, an increase of $74 \%$ [15]. Several large research facilities have also been established. For example, as mentioned in Introduction, Canadian Light Source, Canada' national synchrotron research facility, was launched in Saskatchewan in 2001. It has attracted many researchers to Saskatchewan to conduct research in diverse fields including biomedical research, earth sciences, and environment science. The increase in the average number of patents per year from 3 during the period of 1971-1975 to 30 during the period of 2001-2005 indicates that 
research output has increased and inventive activities have become more and more common in this province.

Worldwide and at Canada national level, the inventive activities in Computers \&

Communications, one of the high-tech fields, have been accelerating since 2003, and its share steadily ranked in the first place with a share of more than $30 \%$ in 2008 . Computers \& Communications field has been the engine for world economic growth since the last two decades. However, patenting activities in the other high-tech field Drugs \& Medical are still slow, ranked at the bottom of the six technology categories both in Canada and in the world. The trend in Saskatchewan is different from the rest of the world. It is known that Saskatchewan's economy has been mainly based on its rich natural resources, and its competitiveness has been largely supported by the traditional resource-based industries. The study results reveal that Saskatchewan is continuing to innovate in traditional fields and traditional technologies in agriculture, mining, and mechanical fields are still the backbone of this province, as reflected by the large number of patents in these traditional technological sectors, particularly in Others and Mechanical sectors. On the other hand, the study finds that Saskatchewan is gradually building its strengths in Drugs \& Medical sector. During last decade, Drugs \& Medical has become the second largest technology sector in Saskatchewan. As a region known for its strength in agriculture industry, it is not surprising that Saskatchewan is choosing its new technological direction towards Drugs \& Medical sector, particularly in biotechnology and drugs sub-sectors. Compared to the other high-tech field Computers \& Communications, the Drugs and Medical sector is more closely related to agricultural technology. This linkage suggests that Saskatchewan has been taking advantage of its traditional strengths in order to achieve a more balanced combination of key technologies, and its development in high technological sector is built upon its traditional key technology.

Trahtenberg introduced the term General Purpose Technology, which plays the role of "engines of growth" [5]. A successful innovative general purpose technology is an essential factor to dictate the growth potential of sustained economies. Computers \& Communications has been recognized as the dominant General Purpose Technology since the last two decades. With the advancement in biotechnology, Ruttan argues that biotechnology will become one of the general purpose technologies in $21^{\text {st }}$ century and the drug and biotechnology industry has huge economical potential [16]. Since Drugs \& Medical is the second most important technology in Saskatchewan, how to realize its economical potential is a topic that the provincial government should pay attention to, as this is the ultimate goal of investment in R\&D. Policy makers should adjust their technological strategies to include encouraging start-up companies and emphasizing technology transfer and commercialization of intellectual properties in these fields.

Since early 1990s, many universities have substantially expanded their R\&D mission to include intellectual properties, namely patents. In this movement, they have been recognized as the resource and drivers for economical innovations [17]. This study finds that the most productive 
contributor to the innovation in this province is the University of Saskatchewan, which holds 114 patents or $19 \%$ of the total patents. A closer examination of its patents found that 96 of the 114 patents are in the field of Drugs \& medical, which is $86 \%$ of the patents in this field owned by the Saskatchewan organizations. This result confirms, from a quantitative perspective, that universities are playing an increasingly important role in new economical development. As the largest research university in this province, the University of Saskatchewan is leading the way in terms of diversifying the provincial technological composition. However, a recent study has concluded that universities are more adept at developing new technologies than transferring the technologies into commercial applications, and the long lag between the discovery of new technologies and its use by firms could seriously impair a region's competitiveness [18]. The policy makers both in the province and in the University should take note of this and develop strategies particularly appropriate for the university environment in order to speed up the technology transfer process.

The results presented here must be taken with caution. It should be noted that counts of granted patents alone does not give a comprehensive assessment of the importance of a technology in a region, other indicators such as employment data, number of companies, or R\&D expenditure in each sector should be considered as well. Future studies are needed in this regard to provide a more robust assessment of innovation and technological performance in this region in conjunction with patent data.

This study has several limitations in its methodological design. First, this study investigated granted patents instead of patent applications due to the fact that U.S. patent applications are only accessible from 2001. There is a time lag of three to five years for a patent to be granted, therefore, the number of granted patents would not reflect the most current inventive activities. Second, this study used patent issuing date to compile the statistics in order to be consistent with the data obtained from USPTO statistical reports [19]. Because of the time lag mentioned above, inventions applied in different years may be counted together by the year of issuing. This can introduce biases during periods when technology is undergoing rapid change or for regions in which technology is growing rapidly [1]. Third, assignee address was used to allocate patents to the region, which reflect the ownership of patents by Saskatchewan firms, regardless of where the researches were conducted. It is possible that assignee address may not correspond to the place of inventive activities; therefore it may not fully reveal patent activities in this region.

\section{Conclusion}

Patent information has recently become the focus of research in the business field because it provides an effective way to analyse the strengths and weaknesses of technological competitiveness of an organization or a region. Many researchers have studied patent information in order to have a comprehensive understanding of technological development 
history, technological trends, and technological potentials. This study is the first attempt to identify areas of strength and trends in Saskatchewan's technologies.

This research shows that inventive activities is steadily growing and the technological development of Saskatchewan has experienced three stages. The initial stage of $1971-1985$ heavily emphasized traditional agricultural and natural resource-based technology (Others field). In the emerging stage of 1986-1995, the new advanced technology in Drugs \& Medical fields became an important player while traditional technological sectors were still prominent. A greater balance among technology sectors was seen during the developing stage of 19962009, when Drugs \& Medical counted for almost one third of the patent activities. The core technological specializations in Saskatchewan include technologies in agricultural fields, drugs and biotechnology fields, and mining fields.

The technological development in Saskatchewan is different from Canada and the rest of the world. While Computers \& Communications has been the dominant patenting field since 2003 both in Canada and in the world, Saskatchewan is continuing to invent in traditional fields but is gradually building its strengths in Drugs \& Medical field. As one of the high-tech fields, Drugs \& Medical has the potential to become the engines of economic growth in this era. The study results provide a possibility to diversity the provincial economy if policy makers develop strategies to facilitate transfer of the new technological developments in the Drugs \& Medical field to industries.

\section{Acknowledgement}

This research was supported by the Dean's Research and Innovation Fund, University of Saskatchewan Library. The author thanks Erin Watson for valuable feedback.

\section{References}

[1] Organisation for Economic Co-Operation and Development. OECD Patent Statistics Manual. 2009.

[2] Basberg BL. Patent statistics and the measurement of technological change-an assessment of the Norwegian patent data, 1840-1980. World Patent Information 1984;6(4):158-164.

[3] Grupp H, Lacasa ID, Schmoch U. Tracing technological change over long periods in Germany in chemicals using patent statistics. Scientometrics 2003;57(2):175-195.

[4] Chen D, Chang H, Huang M, Fu F. Core technologies and key industries in Taiwan from 1978 to 2002: a perspective from patent analysis. Scientometrics 2005;64(1):31-53. 
[5] Trajtenberg M. Is Canada missing the 'technology boat'? Evidence from patent data. In: Rao S, Sharpe A, ed. Productivity Issues in Canada. Calgary, Canada: University of Calgary Press; 2002. 245-80.

[6] Yegul MF, Yavuz M, Guild P. Nanotechnology: Canada's position in scientific publications and patents. In: Portland International Conference on Management of Engineering \& Technology; Cape Town, South Africa. 27-31 July, 2008; 704-13.

[7] Phillips P. Economy of Saskatchewan. in The Encyclopedia of Saskatchewan. 2005. $<$ http://esask.uregina.ca/entry/economy of saskatchewan.html> Accessed February 10, 2010.

[8] Saskatchewan Bureau of Statistics. Economic Review 2008. 2009;62.

$<$ http://www.stats.gov.sk.ca/stats/2008\%20Economic\%20Review> Accessed March 22, 2010

[9] Organisation for Economic Co-Operation and Development. Patents and Innovation: Trends and Policy Challenges. 2004; <http://www.oecd.org/dataoecd/48/12/24508541.pdf> Accessed March 12, 2010.

[10] Global InfoMine. Dynamic Charting Tool: Investment Mine. <http://www.infomine.com/commodities> Retrieved March 22, 2010.

[11] United States Department of Agriculture. National Agricultural Statistics Service Statistics by Subject. 2010; <http://www.nass.usda.gov/Statistics by Subjectindex.asp> Retrieved March 22, 2010.

[12] Bhattacharya S. Mapping inventive activity and technological change through patent analysis: a case study of India and China. Scientometrics 2004;61(3):361-381.

[13] Hall BH, Jaffe AB, Trajtenberg M. The NBER patent citations data file: lessons, insights and methodological tools. 2001;NBER WORKING PAPER SERIES 8498. National Bureau of Economic Research. <http://www.nber.org/papers/w8498> Accessed February 12, 2009.

[14] Organisation for Economic Co-Operation and Development. OECD Countries Spend More on Research and Development, Face New Challenges. 2004;

<http://www.oecd.org/document/2/0,2340,en 26492011853410016211 1 1, 00.html>. Accessed March 12, 2010.

[15] Statistics Canada. Table 358-0001: Domestic spending on research and development (GERD), performing sector, by province. 2009. < http://cansim2.statcan.gc.ca>. Retrieved April 2, 2010

[16] Ruttan VW. Technology, growth, and development :an induced innovation perspective. New York: Oxford University Press; 2001.

[17] Powell WW, Owen-Smith J, Colyvas JA. Innovation and Emulation: Lessons from American Universities in Selling Private Rights to Public Knowledge. Minerva: A Review of Science, Learning and Policy 2007;45(2):121-142. 
[18] Siegel DS, Waldman DA, Atwater LE, Link AN. Toward a model of the effective transfer of scientific knowledge from academicians to practitioners: qualitative evidence from the commercialization of university technologies. Journal of Engineering and Technology Management 2004 03;21(1-2):115-42.

[19] United States Patent and Trademark Office. Patenting By Geographic Region (State and Country), Breakout By Technology Class, CY1963-2008 Utility Patent Grants Distributed By Year of Grant. <http://www.uspto.gov/web/offices/ac/ido/oeip/taf/clsstca/stc cl gd.htm>. Accessed November 5, 2010. 
Figure 1. Number of Saskatchewan Patents by Issuing Year

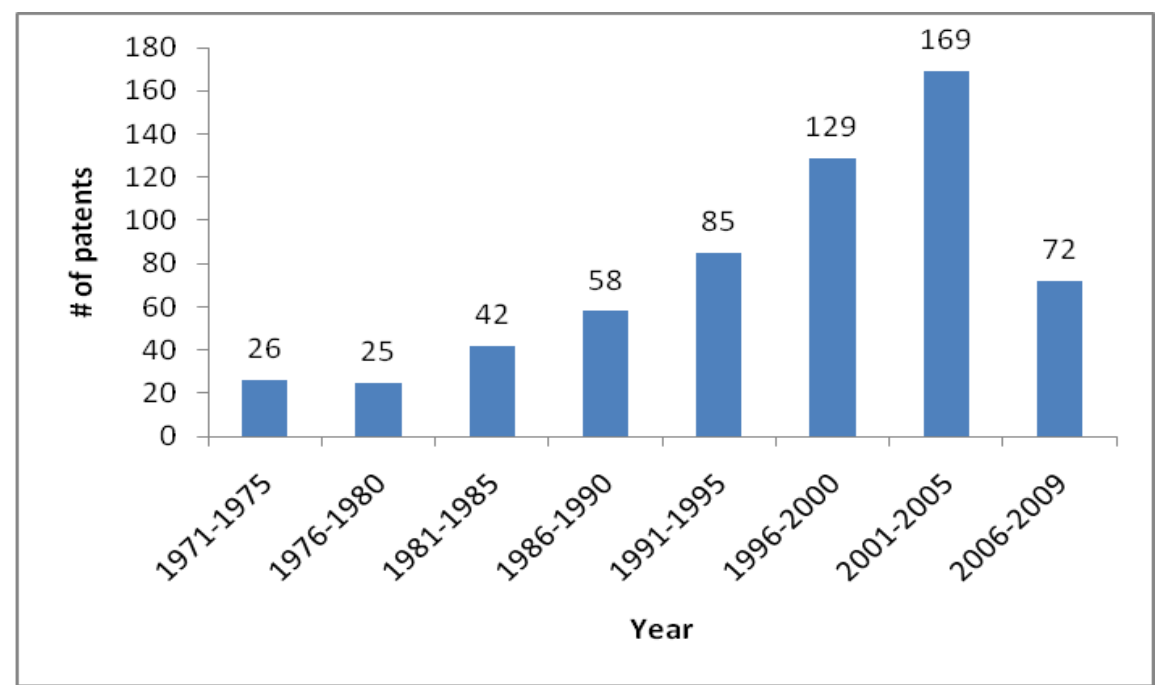

Figure 2. Types of Institution Contributing Patent Activities in Saskatchewan

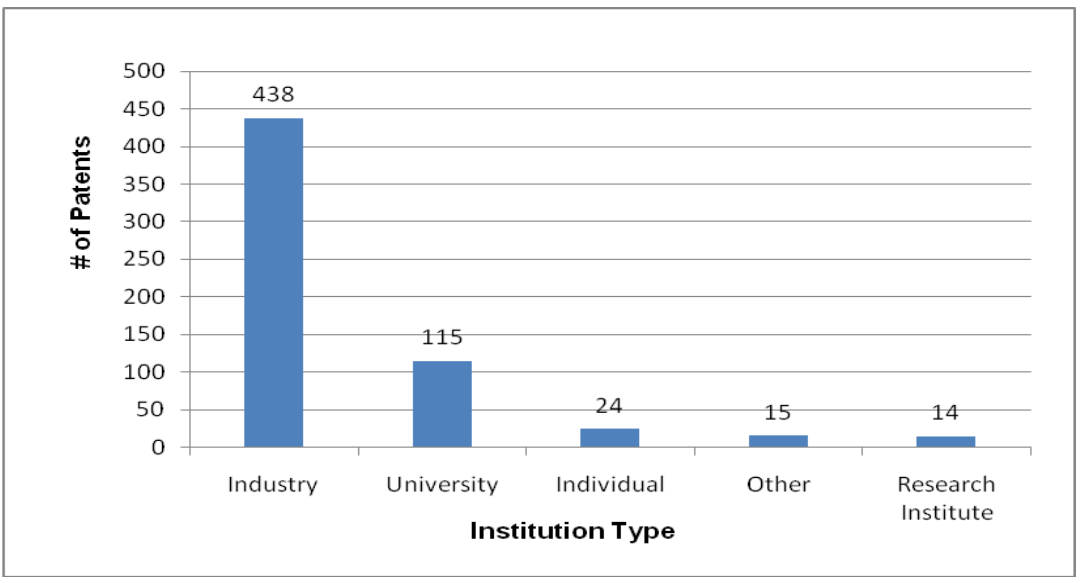


Figure 3. Number of Patents by Technological Category

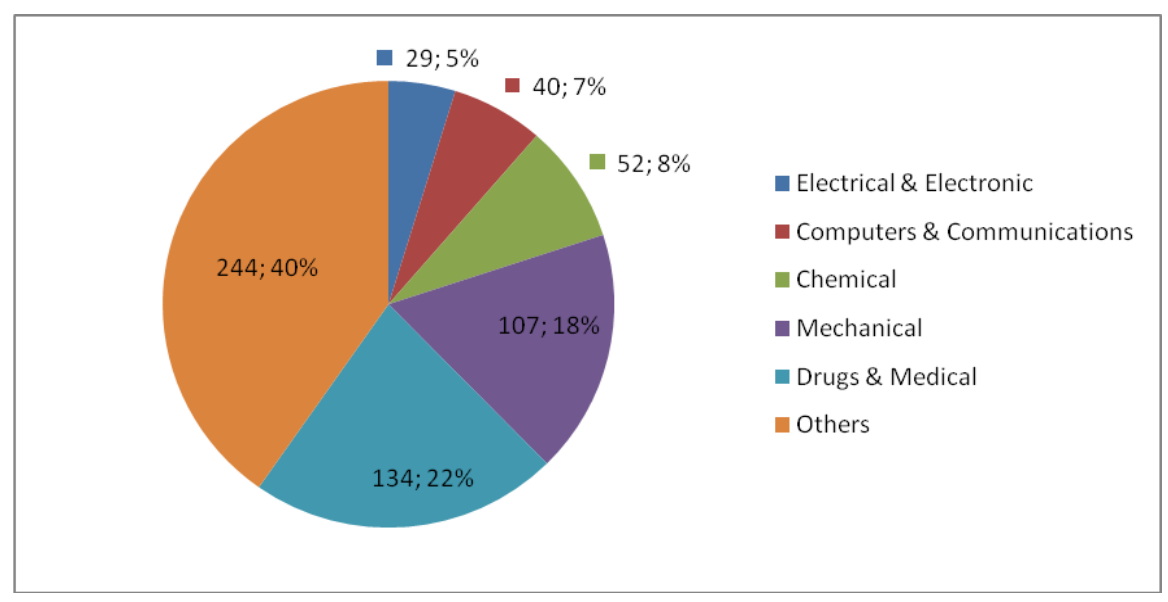


Figure 4. Comparison of Saskatchewan, Canadian, and all USPTO Patents, 1995-2008

\section{Saskatchewan Patents}

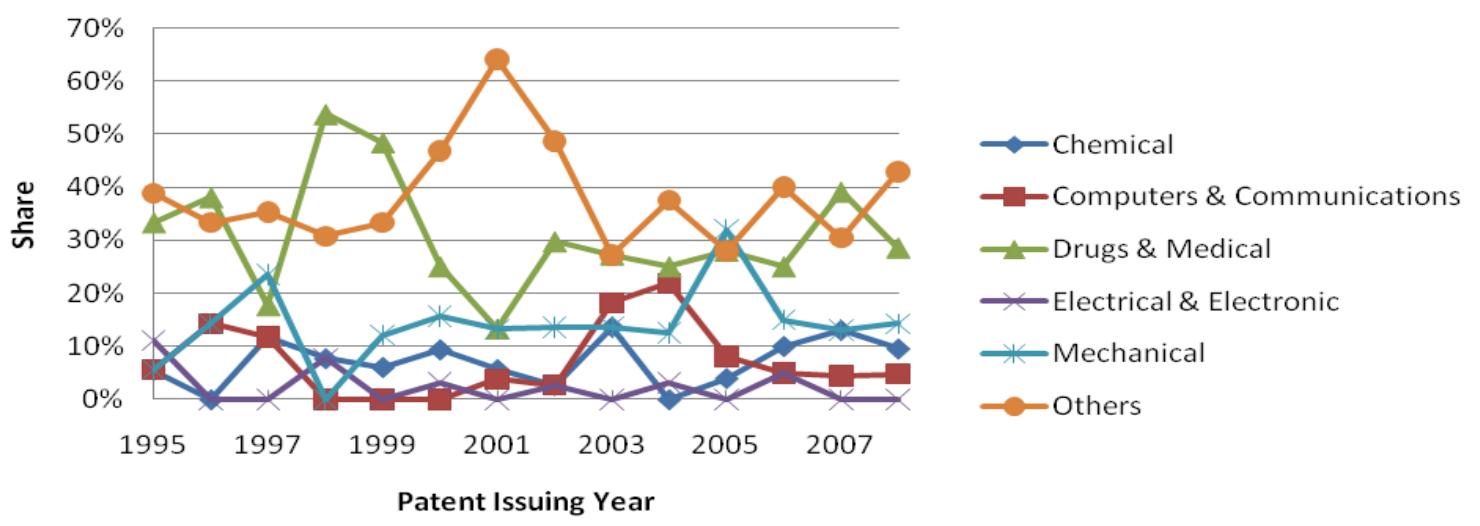

\section{Canadian patents*}

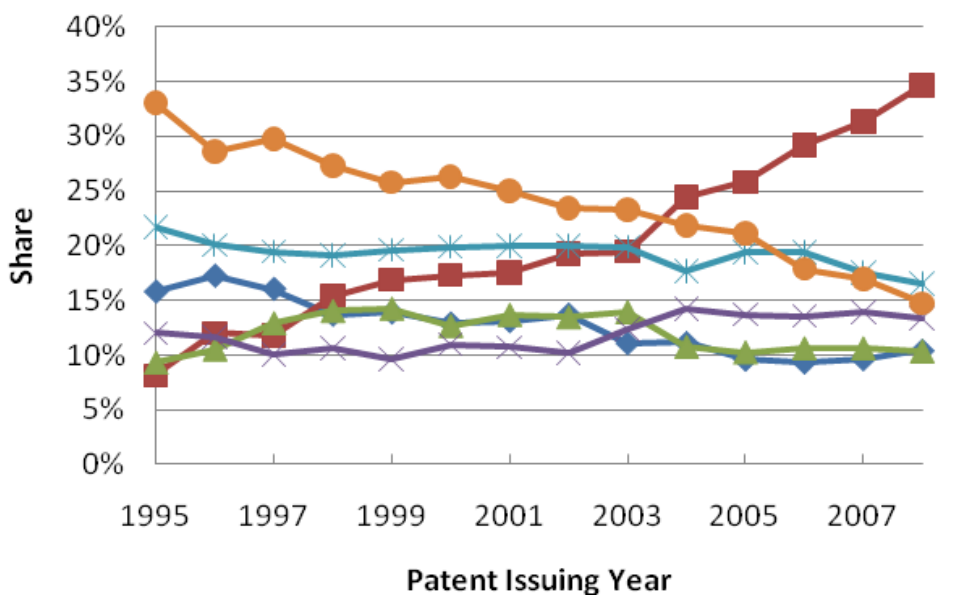

All USPTO Patents*

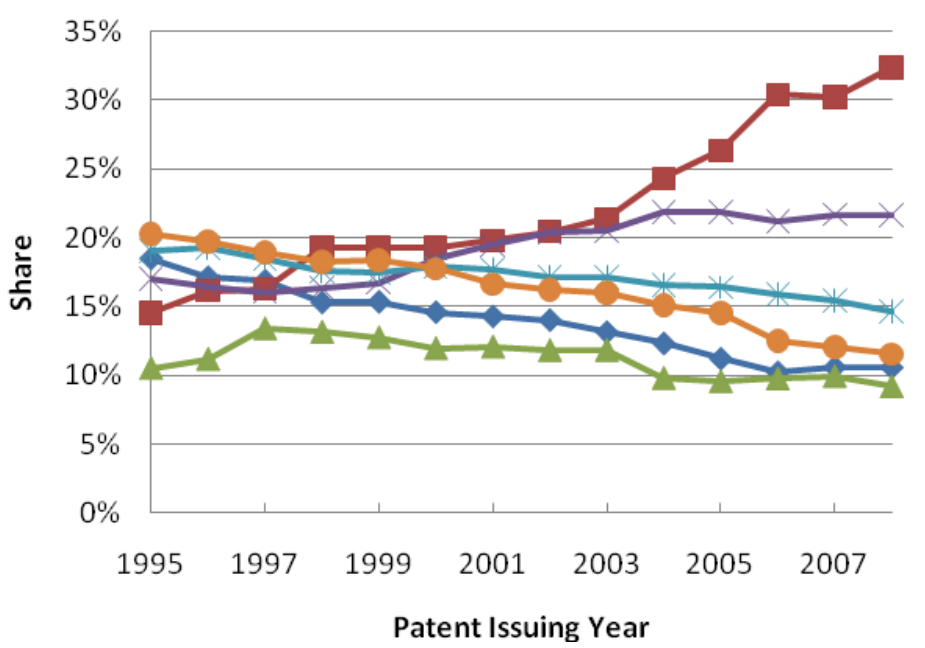

\section{$\leadsto$ Chemical}

- Computers \& Communications

-Drugs \& Medical

$\multimap$ Electrical \& Electronic

*Mechanical

$\longrightarrow$ Others

*Data source: United States Patent and Trademark Office [19]

$\leadsto$ Chemical

$\rightarrow-$ Computers \& Communications

$\leftarrow$ Drugs \& Medical

־Electrical \& Electronic

*Mechanical

$\multimap$ Others 
Table 1. Patent Count of Most Productive Assignees

\begin{tabular}{|l|r|}
\hline Organization & Number of patents \\
\hline University of Saskatchewan & 114 \\
\hline Flexi-Coil Limited & 85 \\
\hline DeGelman Industries Limited & 16 \\
\hline Morris Rob-Weeder Company, Ltd. & 15 \\
\hline PPG Industries Canada Ltd. & 14 \\
\hline Bourgault Industries Ltd & 13 \\
\hline International Road Dynamics & 11 \\
\hline Saskatchewan Power Corporation & 11 \\
\hline
\end{tabular}

Table 2. Key Technological Sectors 1971-1985

\begin{tabular}{|c|l|c|}
\hline Rank & Technology sector & \# of patents (percentage) \\
\hline 1 & Others & $44(47.31 \%)$ \\
\hline 2 & Mechanical & $18(19.35 \%)$ \\
\hline 3 & Chemical & $11(11.83 \%)$ \\
\hline 4 & Electrical \& Electronic & $10(10.75 \%)$ \\
\hline 5 & Computers \& Communications & $8(8.60 \%)$ \\
\hline 6 & Drugs \& Medical & $2(2.15 \%)$ \\
\hline & Total & $93(100 \%)$ \\
\hline
\end{tabular}

Table 3. Key Technological Sectors 1986-1995.

\begin{tabular}{|c|l|c|}
\hline Rank & Technology sector & \# of patents (percentage) \\
\hline 1 & Others & $48(33.57 \%)$ \\
\hline 2 & Mechanical & $37(25.87 \%)$ \\
\hline 3 & Drugs \& Medical & $21(14.69 \%)$ \\
\hline 4 & Chemical & $17(11.89 \%)$ \\
\hline 5 & Electrical \& Electronic & $13(9.09 \%)$ \\
\hline 6 & Computers \& Communications & $7(4.90 \%)$ \\
\hline & Total & $143(100.00 \%)$ \\
\hline
\end{tabular}


Table 4. Key Technological Sectors 1996-2009

\begin{tabular}{|c|l|c|}
\hline Rank & Technology sector & \# of patents (percentage) \\
\hline 1 & Others & $152(41.08 \%)$ \\
\hline 2 & Drugs \& Medical & $111(30.00 \%)$ \\
\hline 3 & Mechanical & $52(14.05 \%)$ \\
\hline 4 & Computers \& Communications & $25(6.76 \%)$ \\
\hline 5 & Chemical & $24(6.49 \%)$ \\
\hline 6 & Electrical \& Electronic & $6(1.62 \%)$ \\
\hline & Total & $370(100.00 \%)$ \\
\hline
\end{tabular}

Table 5. Core Technology Specializations 1971-2009

\begin{tabular}{|l|c|c|}
\hline Technological sub-sectors & \# of patents & Percentage \\
\hline Earth Working \& Wells & 116 & $19.14 \%$ \\
\hline Drugs & 81 & $13.37 \%$ \\
\hline Agriculture, Husbandry, Food & 74 & $12.21 \%$ \\
\hline Miscellaneous-Mechanical & 56 & $9.24 \%$ \\
\hline Biotechnology & 52 & $8.58 \%$ \\
\hline Miscellaneous-Others & 35 & $5.78 \%$ \\
\hline Miscellaneous-Chemical & 33 & $5.45 \%$ \\
\hline Communications & 27 & $4.46 \%$ \\
\hline Transportation & 21 & $3.47 \%$ \\
\hline Materials Processing. \& Handling & 19 & $3.14 \%$ \\
\hline Measuring \& Testing & 16 & $2.64 \%$ \\
\hline Computer Hardware \& Software & 12 & $1.98 \%$ \\
\hline Organic Compounds & 10 & $1.65 \%$ \\
\hline Motors, Engines \& Parts & 9 & $1.49 \%$ \\
\hline Miscellaneous-Elec. & 7 & $1.16 \%$ \\
\hline Heating & 7 & $1.16 \%$ \\
\hline
\end{tabular}


Appendix: Search strategy

(((Saskatchewan or Saskatoon or Regina or Estevan or Humboldt or Lloydminster or Melfort or Melville or Moose Jaw or North Battleford or Prince Albert or Swift Current or Weyburn or Yorkton) and Canada) $<$ in $>$ PA) AND NOT ((fort saskatchewan) $<$ in $>$ PA)

Note: The names of major cities in Saskatchewan were used in the search strategy to ensure a comprehensive search.

The last search string "AND NOT ((fort saskatchewan) <in>PA)" was used to exclude patents with assignee in Fort Saskatchewan because "Fort Saskatchewan" is a city in another province. 